\title{
Growth and membrane fluidity of food-borne pathogen Listeria monocytogenes in the presence of weak acid preservatives and hydrochloric acid
}

\author{
loannis Diakogiannis ${ }^{1}$, Anita Berberi ${ }^{1}$, Eleni Siapi ${ }^{2}$, Angeliki Arkoudi-Vafea ${ }^{1}$, Lydia Giannopoulou ${ }^{1}$ \\ and Sofia K. Mastronicolis ${ }^{1}$ *
}

\author{
${ }^{1}$ Food Chemistry Laboratory, Department of Chemistry, University of Athens, Athens, Greece \\ 2 Institute of Biology, Medicinal Chemistry and Biotechnology, National Hellenic Research Foundation, Athens, Greece
}

\section{Edited by:} Biotechnology and Bioengineering, Portugal

\section{Reviewed by:}

Miguel Cacho Teixeira, Technical University of Lisbon, Portugal Didier Cabanes, Institute for Molecular and Cell Biology, Portugal

\section{*Correspondence:}

Sofia K. Mastronicolis, Food Chemistry Laboratory, Department of Chemistry, University of Athens, Panepistimioupolis Zografou, GR-157 01 Athens, Greece e-mail: smastro@chem.uoa.gr
Nuno Pereira Mira, Institute for

This study addresses a major issue in microbial food safety, the elucidation of correlations between acid stress and changes in membrane fluidity of the pathogen Listeria monocytogenes. In order to assess the possible role that membrane fluidity changes play in L. monocytogenes tolerance to antimicrobial acids (acetic, lactic, hydrochloric acid at low pH or benzoic acid at neutral $\mathrm{pH}$ ), the growth of the bacterium and the gel-to-liquid crystalline transition temperature point $\left(T_{\mathrm{m}}\right)$ of cellular lipids of each adapted culture was measured and compared with unexposed cells. The $T_{m}$ of extracted lipids was measured by differential scanning calorimetry. A trend of increasing $T_{m}$ values but not of equal extent was observed upon acid tolerance for all samples and this increase is not directly proportional to each acid antibacterial action. The smallest increase in $T_{m}$ value was observed in the presence of lactic acid, which presented the highest antibacterial action. In the presence of acids with high antibacterial action such as acetic, hydrochloric acid or low antibacterial action such as benzoic acid, increased $T_{m}$ values were measured. The $T_{m}$ changes of lipids were also correlated with our previous data about fatty acid changes to acid adaptation. The results imply that the fatty acid changes are not the sole adaptation mechanism for decreased membrane fluidity (increased $T_{\mathrm{m}}$ ). Therefore, this study indicates the importance of conducting an in-depth structural study on how acids commonly used in food systems affect the composition of individual cellular membrane lipid molecules.

Keywords: Listeria monocytogenes, membrane fluidity, phase transition, DSC, acid stress response, preservatives, weak acids, hydrochloric acid

\section{INTRODUCTION}

Listeria monocytogenes has been associated with a variety of food products, including dairy foods, meat, poultry, and seafood as well as fruits and vegetables (Farber and Peterkin, 2000; Mastronicolis et al., 2011). In 2008, 1,381 confirmed human cases of listeriosis were reported in the European Union and the reported casefatality rate was 20.5\% [European Food Safety Authority (EFSA), 2010].

Modification of membrane lipid composition is clearly an important adaptation mechanism in L. monocytogenes, which allows it to grow in a stressful environment such as low temperature (Annous et al., 1997; Mastronicolis et al., 2005); low pH (Giotis et al., 2007; Mastronicolis et al., 2010); presence of disinfectants (Bisbiroulas et al., 2011); pressure; ion concentrations etc. (Beales, 2004). Changes in lipid composition can lead to changes in cytoplasmic membrane fluidity (Mykytczuk et al., 2007).

The term "membrane fluidity" is a convenient one to summarize a multifaceted phenomenon that has contributions from molecular packing (order) and molecular motions (viscosity; Russell, 2002). Membranes can exist in different phases and the most consistent phase transition is the one occurring when the membrane passes from a tightly ordered "gel" or "solid" phase to a liquid-crystal phase which is the active state of the membrane. A widely used method for determining the phase transition temperature $\left(T_{\mathrm{m}}\right)$ is calorimetry. The influence of hydrocarbon chain length, branching and unsaturation, as well as the head group of the membrane lipids on the value of $T_{\mathrm{m}}$, is considerable. In general, increasing the chain length, decreasing the branching or increasing the saturation of the chains increases the phase transition temperature (New, 1994; Mykytczuk et al., 2007).

Weak lipophilic acids can occur naturally in many fruits and vegetables and have been widely used to maintain microbial stability in low $\mathrm{pH}$ foods. Weak acid preservatives affect the cells' ability to maintain $\mathrm{pH}$ homeostasis, disrupting substrate transport and inhibiting metabolic pathways (Beales, 2004). The effect of many weak acid preservatives is dependent on the fluidity and permeability of the cytoplasmic membrane, since it is the first barrier to encounter the stress and any sensing mechanism would be located within it (Beales, 2004; López et al., 2006). Changes in the lipid profile of the plasma membrane may alter membrane permeability and fluidity, which may in turn contribute to tolerance (Beales, 2004).

In our previous report on the effects of different acidic stresses such as hydrochloric, acetic, and lactic acid ( $\mathrm{pH} 5.5$ ) or benzoic 
acid ( $\mathrm{pH} 7.3$ ) on L. monocytogenes total, polar and neutral lipid compositional changes, our results suggest that only low $\mathrm{pH}$ value enhances the antimicrobial activity of an acid, though irrespective of $\mathrm{pH}$, the acid adaptation response leads to a similar alteration in fatty acid composition, mainly originating from the neutral lipid class of adapted cultures (Mastronicolis et al., 2010). However, the effects of the aforementioned acidic antimicrobials on membrane fluidity in L. monocytogenes have not been determined and compared to date. The present work was intended to provide new data by determining and comparing modifications in $T_{\mathrm{m}}$ of L. monocytogenes membrane lipids (and thus alterations in membrane fluidity) in response to acid stress induced by acids such as hydrochloric, acetic, lactic, or benzoic acids and also to correlate the fatty acid compositional changes of each acid-adapted culture (from our previous data) with the lipid thermodynamic behavior in order to clarify if modifications in the membrane physical state of adapted cells act as a defense mechanism against acid stress.

\section{MATERIALS AND METHODS CULTURE OF THE ORGANISM}

An avirulent strain L. monocytogenes, DP-L1044 (D. Portnoy, University of Pennsylvania) prepared by a transposon insertion (Camilli et al., 1991) in the parent strain (Lm10403S), was grown in brain heart infusion broth (BHI, Difco Laboratories) at $30^{\circ} \mathrm{C}$ $(24 \mathrm{~h})$. A $10 \mathrm{~mL}$ aliquot of this was then inoculated into $1 \mathrm{~L}$ of BHI broth, which was then incubated at $30^{\circ} \mathrm{C}\left(\mathrm{Lm}_{\text {control }}\right)$ until early stationary phase. Four aliquots $(10 \mathrm{~mL})$ of the same stock were then inoculated, respectively, into $1 \mathrm{~L} \mathrm{BHI}$ that were adjusted to $\mathrm{pH}_{\text {initial }} 5.5$ with (i) $\mathrm{HCl}\left(\mathrm{Lm}_{\mathrm{HCl}}\right)$; (ii) L-lactic acid (Fluka, PA, USA; Lm LA $_{\text {}}$ ); and (iii) acetic acid (Merck, PA, USA; Lm AA $_{\text {) }}$. Another $10 \mathrm{~mL}$ aliquot was used to inoculate $1 \mathrm{~L} \mathrm{BHI}$ with the addition of $1.00 \mathrm{~g}$ benzoic acid (Merck, PA, USA; $\mathrm{Lm}_{\mathrm{BA}}$ ) $\mathrm{pH}_{\text {initial }}$ 7.3. All the above cultures were incubated at $30^{\circ} \mathrm{C}$ until early stationary phase. The growth of L. monocytogenes for each treatment over time was determined by measuring absorbance (OD) at $600 \mathrm{~nm}$.

\section{EXTRACTION OF TOTAL LIPIDS}

From each culture, cells pelleted by centrifugation $\left(4^{\circ} \mathrm{C}, 5877 \times g\right)$ were washed twice in phosphate buffer $(\mathrm{pH} 7.0)$. Extraction of total lipids performed essentially by extraction with chloroform/methanol $(2 / 1 \mathrm{v} / \mathrm{v})$ and washing the extract with 0.2 volumes of water (Folch et al., 1957). After phase equilibration, the lower chloroform layer (total lipids) was dried under nitrogen.

\section{DIFFERENTIAL SCANNING CALORIMETRY ANALYSIS}

Two sets of extracted total lipids from each acid-adapted or nonadapted culture were utilized for differential scanning calorimetry (DSC) analysis. Each set of extracted total lipids was collected from one culture, in the case of $\mathrm{Lm}_{\text {control }}$ and of $\mathrm{Lm}_{\mathrm{BA}}$, or by harvesting two cultures in the case of $\mathrm{Lm}_{\mathrm{AA}}$ and $\mathrm{Lm}_{\mathrm{HCl}}$, in order to obtain the appropriate weight of lipids for DSC analysis (4-5 mg). Notably, in the case of Lm $\mathrm{LA}_{\mathrm{LA}}$, one set of extracted total lipids was used because the appropriate weight of lipids for DSC analysis was collected by harvesting five cultures.

Portions of the samples (approximately $4 \mathrm{mg}$ ) were weighed in stainless-steel capsules obtained from PerkinElmer (Norwalk,
CT, USA) and sealed. Thermal scans were obtained using a PerkinElmer DSC-7 calorimeter and Pyris software for Windows. All samples were scanned from -25 to $80^{\circ} \mathrm{C}$ until identical thermograms were obtained, using a scanning rate of $10^{\circ} \mathrm{C} \mathrm{min}^{-1}$. The temperature scale of the calorimeter was calibrated using indium $\left(T_{\mathrm{m}}=156.6^{\circ} \mathrm{C}\right)$ and dipalmitoylphosphatidylcholine from Avanti Polar Lipids Inc. (Alabaster, AL, USA) bilayers $\left(T_{\mathrm{m}}=41.2^{\circ} \mathrm{C}\right)$. The following diagnostic parameters in the observed endothermic events were recorded during the phase transition and are used for the study of lipids: $T_{\mathrm{m}}$ (maximum of the temperature peak), and $\Delta \mathrm{H}$ (the area under the peak represents the enthalpy change during the transition).

The repeatability of the thermograms and reversibility of the transitions were checked after each run by re-heating the sample after cooling. All samples were scanned a minimum of three times.

\section{STATISTICAL ANALYSIS}

The results were evaluated by analysis of variance (ANOVA). T-test for unpaired observations was tested at a confidence level of 95\%.

\section{RESULTS}

Growth of L. monocytogenes in BHI medium with time was determined for each treatment by measuring absorbance (OD) at $600 \mathrm{~nm}$ and shown in Figure 1. The presence of lactic, acetic, or hydrochloric acid at $\mathrm{pH} 5.5$ was accompanied by low survival $(P<0.01)$, while cells grown at neutral $\mathrm{pH}$ in the presence of benzoic acid displayed little antilisterial activity $(P<0.05)$. The obtained $\mathrm{OD}_{600}$ values were at early stationary phase: $\mathrm{Lm}_{\text {control }}$ $0.811 \pm 0.010,10 \mathrm{~h} ; \mathrm{Lm}_{\mathrm{LA}} 0.096 \pm 0.018,168 \mathrm{~h} ; \mathrm{Lm}_{\mathrm{AA}}$ $0.217 \pm 0.019,72 \mathrm{~h} ; \mathrm{Lm}_{\mathrm{HCl}} 0.320 \pm 0.014,24 \mathrm{~h}$; and $\mathrm{Lm}_{\mathrm{BA}}$ $0.694 \pm 0.019,10 \mathrm{~h}$.

\section{$\mathbf{L m}_{\text {control }}$ CELLS}

The DSC analysis revealed $T_{\mathrm{m}}$ value $25.78 \pm 1.06^{\circ} \mathrm{C}$ as well as enthalpy difference $(\Delta \mathrm{H}) 8.99 \pm 0.557 \mathrm{~J} \mathrm{~g}^{-1}$ (Table 1 and Figure 2).

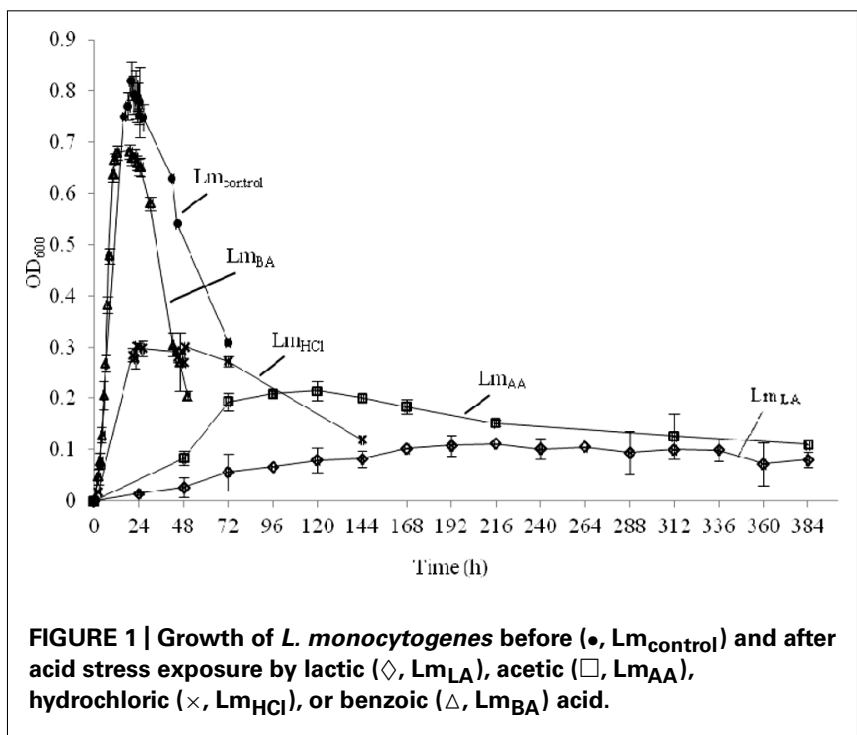


Table 1 | Data from differential scanning calorimetry analysis of $L$. monocytogenes total lipids before ( $\mathbf{L m}_{\text {control }}$ ) and after acid stress exposure by lactic $\left(\operatorname{Lm}_{\mathrm{LA}}\right)$, acetic $\left(\mathrm{Lm}_{\mathrm{AA}}\right)$, hydrochloric $\left(\operatorname{Lm}_{\mathrm{HCl}}\right)$, or benzoic $\left(\mathrm{Lm}_{\mathrm{BA}}\right)$ acid.

\begin{tabular}{|c|c|c|c|c|}
\hline & Lm $_{\text {control }}$ & $\operatorname{Lm}_{\mathrm{AA}}$ & $\mathrm{Lm}_{\mathrm{HCl}}$ & $\mathbf{L m}_{\mathrm{BA}}$ \\
\hline \multirow[t]{2}{*}{$T_{\mathrm{m}}\left({ }^{\circ} \mathrm{C}\right)$} & $25.78 \pm 1.06$ & $29.35 \pm 0.23^{\mathrm{a}}\left(T_{\mathrm{m} 1}\right)$ & $29.23 \pm 0.21^{\mathrm{a}}\left(T_{\mathrm{m} 1}\right)$ & $30.25 \pm 2.01^{a}$ \\
\hline & & $34.72 \pm 2.28^{\mathrm{a}}\left(T_{\mathrm{m} 2}\right)$ & $32.28 \pm 0.56^{\mathrm{a}}\left(T_{\mathrm{m} 2}\right)$ & \\
\hline$\Delta \mathrm{H}\left(\mathrm{J} \mathrm{g}^{-1}\right)$ & $8.990 \pm 0.557$ & $14.921 \pm 0.168^{b}$ & $8.246 \pm 0.178$ & $11.618 \pm 0.401^{\circ}$ \\
\hline$\Sigma \mathrm{BCFA} / \Sigma \mathrm{SSCFA} \mathrm{C}^{\mathrm{C}}$ & 8.3 & 1.6 & 2.1 & 2.6 \\
\hline
\end{tabular}

$T_{\mathrm{m}}$, phase transition temperature; $\Delta \mathrm{H}$, enthalpy difference.

a Values statistically increased compared to $L m_{\text {control }}, P<0.05$.

bValues statistically increased compared to $L m_{\text {control }}, P<0.01$.

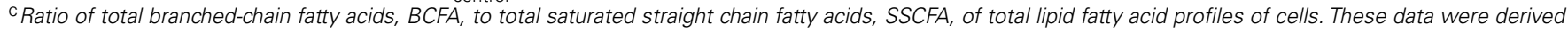
from our previous study (Mastronicolis et al., 2010).

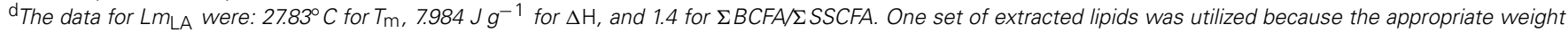
of lipids for DSC analysis was collected by harvesting five cultures.

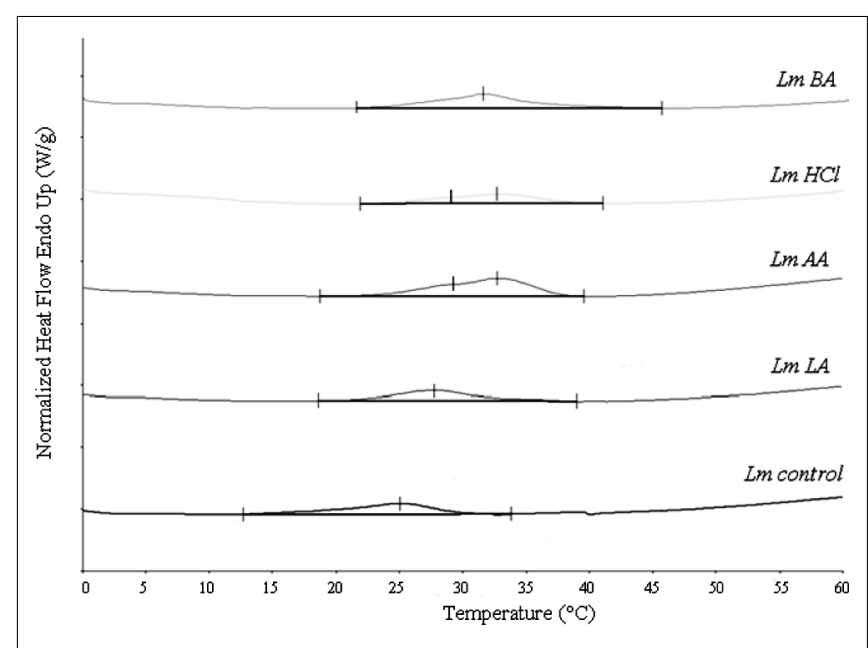

FIGURE 2 | Differential scanning calorimetry curves of L. monocytogenes total lipids, before $\left(\mathrm{Lm}_{\text {control }}\right)$ and after acid stress exposure by lactic $\left(\operatorname{Lm}_{\mathrm{LA}}\right)$, acetic $\left(\operatorname{Lm}_{\mathrm{AA}}\right)$, hydrochloric $\left(\mathrm{Lm}_{\mathrm{HCl}}\right)$, or benzoic $\left(\operatorname{Lm}_{\mathrm{BA}}\right)$ acid.

\section{$\mathrm{Lm}_{\mathrm{AA}}$ AND $\mathrm{Lm}_{\mathrm{HCl}}$ CELLS}

The DSC analysis of each sample revealed two distinct peaks of increased $T_{\mathrm{m}}$ values $\left(T_{\mathrm{m} 1}\right.$ and $\left.T_{\mathrm{m} 2}\right)$ compared to $\mathrm{Lm}_{\text {control }}$. The $\mathrm{Lm}_{\mathrm{AA}}$ sample showed differences of +3.57 and $+8.94^{\circ} \mathrm{C}$ for $T_{\mathrm{m} 1}$ and $T_{\mathrm{m} 2}$, respectively $(P<0.05)$, also $\mathrm{Lm}_{\mathrm{HCl}}$ sample showed differences of +3.45 and $+6.50^{\circ} \mathrm{C}$, respectively $(P<0.05)$.

\section{Lm LA CELLS}

In the DSC analysis an increased $T_{\mathrm{m}}$ value was measured, in which the difference was $+2.05^{\circ} \mathrm{C}$ higher than $\mathrm{Lm}_{\text {control }}$.

\section{$\mathrm{Lm}_{\mathrm{BA}}$ CELLS}

In the DSC analysis an increased $T_{\mathrm{m}}$ value was measured, in which the difference was $+4.47^{\circ} \mathrm{C}$ higher than $\operatorname{Lm}_{\text {control }}(P<0.05)$.

As concerns the $\Delta \mathrm{H}$ values for each instance of acid-adapted cells, the observed changes were as follows: $\operatorname{Lm}_{\mathrm{AA}}: 66 \%(P<0.01)$, $\mathrm{Lm}_{\mathrm{BA}}$ : $29.2 \%(P<0.05)$, increase compared to $\mathrm{Lm}_{\text {control }}$. For the rest samples the $\Delta \mathrm{H}$ values were similar to $\mathrm{Lm}_{\text {control }}$ (Table 1).

\section{DISCUSSION}

Other authors examined the antilisterial effects of these acids. Ravichandran et al. (2011) observed that benzoic acid (5 g/L) demonstrated antimicrobial activity against $L$. monocytogenes after $72 \mathrm{~h}$ incubation at $37^{\circ} \mathrm{C}$. Heavin et al. (2009) observed that benzoic acid was more effective at inhibiting growth of L. monocytogenes than acetic acid, in a medium with a $\mathrm{pH}$ of 6.4 (acidified with $\mathrm{HCl}$ ). Hydrochloric, lactic, and acetic acids at $\mathrm{pH} 3.5$ gave similar kill curves (O'Driscoll et al., 1996). Hydrochloric acid caused low survival of L. monocytogenes at pH 5 (Karatzas et al., 2010) and slight antibacterial action against L. monocytogenes was observed with acetic acid at pH 5 (Chavant et al., 2004). In contrast, Vasseur et al. (1999) observed that the antilisterial effect was: acetic acid > lactic acid $>$ hydrochloric acid. Similar results were observed by Bonnet and Montville (2005) in L. monocytogenes growing at pH 3.5. Phan-Thanh et al. (2000) also found that acetic acid had a more deleterious effect on L. monocytogenes than hydrochloric acid did. Exposure to lactic acid at $\mathrm{pH} 4.0$ totally inactivated $L$. monocytogenes, whereas exposure at $\mathrm{pH} 4.5$ had inhibitory effect (at 5 or $10^{\circ} \mathrm{C}$ ), therefore, even small differences in $\mathrm{pH}$, such as 0.5 units, may have a major impact on the survival of pathogens and hence, on food safety (Tiganitas et al., 2009). The comparative study of acid habituation of L. monocytogenes, under the same experimental conditions is important for the identification of differences between the survival of the pathogen, as comparison between laboratories is difficult because of variation in the assay conditions used (exact $\mathrm{pH}$ value, bacterial strains, incubation temperatures, etc.).

This study provides a first approach to observing the role of phase transitions of membrane lipids (membrane fluidity) in the acid adaptation response of L. monocytogenes. We have previously studied the lipid composition of L. monocytogenes cells grown in the presence of various acids (hydrochloric, acetic, lactic, and benzoic acid) and the analysis of membrane lipids revealed that $L$. monocytogenes similarly altered its fatty acid composition by incorporation more straight (mostly $\mathrm{C}_{16: 0}, \mathrm{C}_{18: 0}$, and $\mathrm{C}_{14: 0}$ ) and fewer branched-chain fatty acids into its membrane independently of the acid utilized (Table 1; Mastronicolis et al., 2010). It is expected that these fatty acids changes lead to membranes with decreased fluidity and low permeability properties (Kaneda, 1991; Zhang and Rock, 2008). In the current study, the measured lipid $T_{\mathrm{m}}$ value of 
each set of adapted cells was increased compared to $\mathrm{Lm}_{\text {control }}$ and this observation is interpreted by the above fatty acid compositional changes. However, the increases in $T_{\mathrm{m}}$ values are not of equal extent and therefore are not absolutely reflected by the acyl chain compositional changes. This fact indicates that fatty acid changes may be crucial but they are not the sole mechanism by which $L$. monocytogenes perceives the acid stress (alters its membrane lipids). Furthermore, the growth of L. monocytogenes in the presence of hydrochloric, lactic, and acetic acid at $\mathrm{pH} 5.5$ caused an increase of neutral lipid percentages (Mastronicolis et al., 2010).

Hydrochloric acid will be dissociated, whereas acetic $\left(\mathrm{pK}_{\mathrm{a}}=4.74\right)$ and lactic acid $\left(\mathrm{pK}_{\mathrm{a}}=3.79\right)$ will be undissociated at $\mathrm{pH}$ 5.5. The latter form of both organic acids is membranepermeable and thus allows acetic and lactic acid to enter the microbial cell. In this work, when the cells were grown in the presence of acetic or hydrochloric acid, the highest $T_{\mathrm{m}}$ values and low survival were observed (Figure 1; Table 1), suggesting that the decrease in membrane fluidity was related to low survival. However, this tendency was reversed in the case of lactic acid, which caused the highest antimicrobial action (Figure 1) in L. monocytogenes cells and these data cannot be explained by a modification in membrane fluidity, which was minimal. This suggests that the membrane fluidity can serve only as a preliminary tool to make predictions concerning the viability of cells. Also, another interesting point was that acetic and hydrochloric acid caused two distinct phase transition points: lipids with different fatty acyls as well as different head groups, whose $T_{\mathrm{m}}$ values differ greatly from each other, undergoing phase transitions independently, and forming membranes composed of two or more separate phases. If the fatty acyls or the head groups have similar $T_{\mathrm{m}}$ values, a main transition intermediate in temperature between those of the individual components will be given (New, 1994). Mykytczuk et al. (2010) also observed decreases in membrane fluidity along with two distinct phase transition points in some strains of Acidithiobacillus ferrooxidans in sub-optimal $\mathrm{pH}$.

Benzoic acid $\left(\mathrm{pK}_{\mathrm{a}}=4.19\right)$ at $\mathrm{pH} 7$ will be in its dissociated form (benzoic anion) and this form is less membrane-permeable and thus does not facilitate its entrance to the microbial cell. The used amount of benzoic acid ( $1 \mathrm{~g} / \mathrm{L}$ culture) did not reduce the $\mathrm{pH}$ of the medium. In order to reduce the $\mathrm{pH}$ value, even more amount of benzoic acid might be added (that is inappropriate for food systems) or one more acid should be added along to benzoic acid (that it is out of the aim of the current work, which was the study of each acid separately). Unlike the rest of the acids utilized, in the presence of benzoic acid the percentage of neutral lipid class remains constant but the decrease of negatively charged phospholipids, such as cardiolipin or phosphatidylglycerol (Mastronicolis et al., 2010), leads to a decrease in membrane fluidity, i.e., increased $T_{\mathrm{m}}$ value (New, 1994), and the data of the present study are consistent with this increase in $T_{\mathrm{m}}$. Furthermore, high $T_{\mathrm{m}}$ value and low antibacterial action (Figure 1; Table 1) was observed, suggesting that the decrease in membrane fluidity was related to the low antibacterial activity of benzoic acid. The low antibacterial action of benzoic acid might be arisen from the neutral $\mathrm{pH}$ of the medium. Relevant to our current work in the case of benzoic acid, Alonso-Hernando et al. (2010) also observed that decreased membrane fluidity in $L$. monocytogenes was correlated to survival upon acid stress, suggesting that adaptation to acid decontaminants is related to changes in membrane fluidity.

Listeria monocytogenes and Salmonella enterica cells exposed to sub-inhibitory concentrations of acid decontaminants (citric acid and peroxyacids) showed decreased membrane fluidity (Alonso-Hernando et al., 2010). In sub-optimal pH, a decrease in membrane fluidity of $A$. ferrooxidans was observed and this is likely linked to the overall increase in saturated fatty acids at the expense of unsaturated fatty acids (Mykytczuk et al., 2010). Adaptation to acid and starvation stress increased net cell hydrophobicity and decreased membrane fluidity of L. innocua (Moorman et al., 2008). ATR(+) L. monocytogenes cells [cells exposed to mild acid $(\mathrm{pH} 5.5)$, which are subsequently able to resist severe acid $(\mathrm{pH}$ $3.5)$ conditions] had lower membrane rigidities than ATR $(-)$ cells (cells subjected at pH 3.5 directly; Najjar et al., 2009). After exposure to oregano essential oil concentrations up to $0.50 \%$, the membrane fluidity of L. monocytogenes was decreased presumably to block, or at least to reduce essential oil entrance and partition into the membrane (Serio et al., 2010). Growth in the presence of butyrate, leucine, valine, isovalerate, or isobutyrate increased the calculated (theoretical estimation) transition temperature of L. monocytogenes cells, because of the decrease of branched-chain at the expense of saturated-chain fatty acids (Julotok et al., 2010). Increase in phase transition temperatures was observed with increased osmotic pressure in Saccharomyces cerevisiae (Laroche et al., 2001). Decreased membrane fluidity was also observed in Bacillus subtilis subjected to osmotic pressure (López et al., 2006).

An understanding of phase transitions and fluidity of membranes is important; since the phase behavior of a membrane determines such properties as permeability, fusion, aggregation, and protein binding, affects critical biochemical reactions, transport systems, all of which can markedly affect the stability of membranes, and their behavior in the cell (New, 1994; Yuk and Marshall, 2006). Acid habituation of pathogens may enhance survival in an acidic food or in the stomach and subsequently cause infection after ingestion. The resistance or adaptation of pathogens to such conditions affect food safety and thus is clearly of significance to the food industry (Beales, 2004).

Although the acid adaptation response of L. monocytogenes altered the fatty acid composition similarly, irrespective of the acid utilized (Mastronicolis et al., 2010), in the present study observed $T_{\mathrm{m}}$ values were increased but not equally. This suggests that the $T_{\mathrm{m}}$ value (membrane fluidity) of lipids does not depend only on the acyl constituent, but also on the total composition and nature of the lipid molecular structure (e.g., phospho-, glyco-, amino-head groups for polar lipids or the specific lipid molecule for neutral lipids, e.g., diclycerides, esters, waxes, etc.). Thus, understanding the physical chemistry of membrane lipids is important in the sense that the characteristics of lipid species, and their heterogeneity, all affect biological membranes. Our current understanding of the role of individual lipid species in a heterogeneous lipid matrix and the specific lipid-lipid and lipid-protein interactions is still far from comprehensive. Therefore, one conclusion of this study would support the in-depth identification of the membrane polar and neutral lipid molecules of L. monocytogenes cells in the presence of the acids utilized. Furthermore, in this study an avirulent 
mutant strain was used. Previous studies have revealed that this strain has similar fatty acid composition as wild strains in optimal condition of growth or in cold adaptation (Annous et al., 1997; Mastronicolis et al., 1998, 2010; Chihib et al., 2003; Julotok et al., 2010), thus we suppose that this mutation will have no impact on the present results response to acids. However, more studies may be required with more strains in order these results to be confirmed because there are not sufficient studies in this field.

\section{REFERENCES}

Alonso-Hernando, A., Alonso-Calleja, C., and Capita, R. (2010). Effects of exposure to poultry chemical decontaminants on the membrane fluidity of Listeria monocytogenes and Salmonella enterica strains. Int. J. Food Microbiol. 137, 130-136. doi: 10.1016/j.ijfoodmicro.2009.11.022

Annous, B. A., Becker, L. A., Bayles, D. O., Labeda, D. P., and Wilkinson, B. J. (1997). Critical role of anteisoC15:0 fatty acid in the growth of Listeria monocytogenes at low temperatures. Appl. Environ. Microbiol. 63, 3887-3894.

Beales, N. (2004). Adaptation of microorganisms to cold temperatures, weak acid preservatives, low $\mathrm{pH}$, and osmotic stress: a review. Compr. Rev. Food Sci. Food Saf. 3, 1-20. doi: 10.1111/j.1541-4337. 2004.tb00057.x

Bisbiroulas, P., Psylou, M., Iliopoulou, I., Diakogiannis, I., Berberi, A., and Mastronicolis, S. K. (2011). Adaptational changes in cellular phospholipids and fatty acid composition of the food pathogen Listeria monocytogenes as a stress response to disinfectant sanitizer benzalkonium chloride. Lett. Appl. Microbiol. 52, 275-280. doi: 10.1111/j.1472765X.2010.02995.x

Bonnet, M., and Montville, T. J. (2005). Acid-tolerant Listeria monocytogenes persist in a model food system fermented with nisin-producing bacteria. Lett. Appl. Microbiol. 40, 237-242. doi: 10.1111/j.1472765X.2005.01661.x

Camilli, A., Goldfine, H., and Portnoy, D. A. (1991). L. monocytogenes mutants lacking phosphatidylinositol specific phospholipase $C$ are avirulent. J. Exp. Med. 173, 751-754. doi: 10.1084/jem.173.3.751

Chavant, P., Gaillard-Martinie, B., and Hébraud, M. (2004). Antimicrobial effects of sanitizers against planktonic and sessile Listeria monocytogenes cells according to the growth phase. FEMS Microbiol. Lett. 236, 241-248.

Chihib, N.-E., Ribeiro da Silva, M., Delattre, G., Laroche,
M., and Federighi, M. (2003). Different cellular fatty acid pattern behaviours of two strains of Listeria monocytogenes Scott A and CNL 895807 under different temperature and salinity conditions. FEMS Microbiol. Lett. 218, 155-160. doi: 10.1111/j.1574-6968. 2003.tb11512.x

European Food Safety Authority (EFSA). (2010). The community summary report on trends, and sources of zoonoses, zoonotic agents, and foodborne outbreaks in the European Union in 2008. EFSA J. 8, 1496. doi: 10.2903/j.efsa. 2010.1496

Farber, J. M., and Peterkin, P. I. (2000). "Listeria monocytogenes," in The Microbiological Safety and Quality of Foods, eds B. M. Lund, T. C. BairdParker, and G. W. Gould (Gaithersburg: Aspen Publisher), 1179-1216.

Folch, J., Lees, M., and Stanley-Sloane, G. H. (1957). A simple method for the isolation and purification of totallipids from animal tissues. J. Biol. Chem. 226, 497-509.

Giotis, E. S., McDowell, D. A., Blair, I. S., and Wilkinson, B. J. (2007). Role of branched chain fatty acid in $\mathrm{pH}$ stress tolerance in Listeria monocytogenes. Appl. Environ. Microbiol. 73, 997-1001. doi: 10.1128/AEM. 00865-06

Heavin, S. B., Brennan, O. M., MorrisInhibition of Listeria monocytogenes by acetate, benzoate, and sorbate: weak acid tolerance is not influenced by the glutamate decarboxylase system. Lett. Appl. Microbiol. 49, 179-185. doi: $10.1111 /$ j.1472765X.2009.02634.X

Julotok, M., Singh, A. K., Gatto, C., and Wilkinson, B. J. (2010). Influence of fatty acid precursors, including food preservatives, on the growth and fatty acid composition of Listeria monocytogenes at 37 and $10^{\circ} \mathrm{C}$. Appl. Environ. Microbiol. 76, 1423-1432. doi: 10.1128/AEM.01592-09

Kaneda, T. (1991). Iso- and anteiso-fatty tion, and taxonomic significance. Microbiol. Rev. 55, 288-302. sey, J. P., and O’Byrne, C. P. (2009). acids in bacteria: biosynthesis, func-

In conclusion, in this study we observed that adaptive response of $L$. monocytogenes to weak or strong acid food preservatives includes an increase in the total lipid $T_{\mathrm{m}}$ (decreased membrane fluidity), decreasing the ability of the weak acid preservatives to pass through the membrane and to act into the microbial cell, and thus conferring protection. Furthermore, decreased membrane fluidity acts as strong defense mechanism in some conditions (in the cases of hydrochloric or acetic acid) or as mild defense mechanism (in the cases of benzoic or lactic acid).

Karatzas, K.-A. G., Brennan, O., Heavin, S., Morrissey, J., and O'Byrne, C. P. (2010). Intracellular accumulation of high levels of $\gamma$-aminobutyrate by Listeria monocytogenes $10403 \mathrm{~S}$ in response to low $\mathrm{pH}$ : uncoupling of $\gamma$-aminobutyrate synthesis from efflux in a chemically defined medium. Appl. Environ. Microbiol. 76, 3529-3537. doi: 10.1128/AEM. 03063-09

Laroche, C., Beney, L., Marechal, P. A., and Gervais, P. (2001). The effect of osmotic pressure on the membrane fluidity of Saccharomyces cerevisiae at different physiological temperatures. Appl. Microbiol. Biotechnol. 56, 249 254. doi: 10.1007/s002530000583

López, C. S., Alice, A. F., Heras, H., Rivas, E. A., and Sánchez-Rivas, C. (2006). Role of anionic phospholipids in the adaptation of Bacillus subtilis to high salinity. Microbiology 152, 605-616. doi: 10.1099/ mic.0.28345-0

Mastronicolis, S. K., Arvanitis, N., Karaliota, A., Litos, C., Stavroulakis, G., Moustaka, H., etal. (2005) Cold dependence of fatty acid profile of different lipid structures of Listeria monocytogenes. Food Microbiol. 22, 213-219. doi: 10.1016/ j.fm.2004.08.002

Mastronicolis, S. K., Berberi, A., Diakogiannis, I., Petrova, E., Kiaki, I., Baltzi, T., et al. (2010). Alteration of the phospho- or neutral lipid content and fatty acid composition in Listeria monocytogenes due to acid adaptation mechanisms for hydrochloric, acetic, and lactic acids at $\mathrm{pH} 5.5$ or benzoic acid at neutral pH. Antonie Van Leeuwenhoek 98 307-316. doi: 10.1007/s10482-0109439-z

Mastronicolis, S. K., Diakogiannis, I., Berberi, A., Bisbiroulas, P., Soukoulis, C., and Tzia, C. (2011). Effect of cold adaptation on the survival of Listeria monocytogenes in ice-cream formulations during long-term frozen storage. Ann. Microbiol. 61, 931-937. doi: 10.1007/s13213011-0216-7

Mastronicolis, S. K., German, J. B., Megoulas, N., Petrou, E., Foka, P., and Smith, G. M. (1998). Influence of cold shock on the fatty-acid composition of different lipid classes of the food-borne pathogen Listeria monocytogenes. Food Microbiol. 15, 299306. doi: 10.1006/fmic. 1997.0170

Moorman, M. A., Thelemann, C. A., Zhou, S., Pestka, J. J., Linz, J. E., and Ryser, E. T. (2008). Altered hydrophobicity and membrane composition in stress-adapted Listeria innocua. J. Food Prot. 71, 182-185.

Mykytczuk, N. C. S., Trevors, J. T., Ferroni, G. D., and Leduc, L. G. (2010). Cytoplasmic membrane fluidity and fatty acid composition of Acidithiobacillus ferrooxidans in response to $\mathrm{pH}$ stress. Extremophiles 14, 427-441. doi: 10.1007/s00792010-0319-2

Mykytczuk, N. C. S., Trevors, J. T., Leduc, L. G., and Ferroni, G. D. (2007). Fluorescence polarization in studies of bacterial cytoplasmic membrane fluidity under environmental stress (review). Prog. Biophys. Mol. Biol. 95, 60-82. doi: 10.1016/j.pbiomolbio.2007.05.001

Najjar, M. Z. B., Chikindas, M. L., and Montville, T. J. (2009). The acid tolerance response alters membrane fluidity and induces nisin resistance in Listeria monocytogenes. Probiotics Antimicrob. Proteins 1, 130-135. doi: 10.1007/s12602-009-9025-8

New, R. R. C. (1994). Liposomes a Practical Approach. New York: Oxford University Press.

O’Driscoll, B., Gahan, C. G. M., and Hill, C. (1996). Adaptive acid tolerance response in Listeria monocytogenes: isolation of an acidtolerant mutant which demonstrates increased virulence. Appl. Environ. Microbiol. 62, 1693-1698. doi: 10.1371/journal.pone.0060123

Phan-Thanh, L., Mahouin, F., and Aligé, S. (2000). Acid responses of Listeria monocytogenes. Int. J. Food Microbiol. 55, 121-126. doi: 10.1038/ 345224a0

Ravichandran, M., Hettiarachchy, N. S., Ganesh, V., Ricke, S. C., and Singh, S. (2011). Enhancement of antimicrobial activities of naturally occurring phenolic compounds by nanoscale 
delivery against Listeria monocytogenes, Escherichia coli O157:H7 and Salmonella typhimurium in broth and chicken meat system. J. Food Saf. 31, 462-471. doi: 10.1111/j.17454565.2011.00322.x

Russell, N. J. (2002). Bacterial membranes: the effects of chill storage and food processing. an overview. Int. J. Food Microbiol. 79, 27-34. doi: 10.1016/S0168-1605(02)00176-9

Serio, A., Chiarini, M., Tettamanti, E., and Paparella, A. (2010). Electronic paramagnetic resonance investigation of the activity of Origanum vulgare L. essential oil on the Listeria monocytogenes membrane. Lett. Appl. Microbiol. 51, 149-157. doi: 10.1177/14744740080150040708

Tiganitas, A., Zeaki, N., Gounadaki, A. S., Drosinos, E. H., and Skandamis,
P. N. (2009). Study of the effect of lethal and sublethal $\mathrm{pH}$ and $\mathrm{a}(\mathrm{w})$ stresses on the inactivation or growth of Listeria monocytogenes and Salmonella typhimurium. Int. J. Food Microbiol. 134, 104-112. doi: 10.1016/j.ijfoodmicro.2009.02.016

Vasseur, C., Baverel, L., Hébraud, M., and Labadie, J. (1999). Effect of osmotic, alkaline, acid or thermal stresses on the growth and inhibition of Listeria monocytogenes. J. Appl. Microbiol. 86, 469476. doi: 10.1046/j.1365-2672.1999. 00686.x

Yuk, H.-G., and Marshall, D. L. (2006). Effect of trisodium phosphate adaptation on changes in membrane lipid composition, verotoxin secretion, and acid resistance of Escherichia coli O157:H7 in simulated gastric fluid. Int. J. Food Microbiol. 106, 39-44. doi: 10.1016/j.ijfoodmicro.2005.05.009

Zhang, Y.-M., and Rock, C. O. (2008). Membrane lipid homeostasis in bacteria. Nat. Rev. Microbiol. 6, 222-233. doi: 10.1038/nrmicro1839

Conflict of Interest Statement: The authors declare that the research was conducted in the absence of any commercial or financial relationships that could be construed as a potential conflict of interest.

Received: 31 December 2012; accepted: 29 May 2013; published online: 14 June 2013.

Citation: Diakogiannis I, Berberi A, Siapi E, Arkoudi-Vafea A, Giannopoulou L and Mastronicolis SK (2013) Growth and membrane fluidity of food-borne pathogen Listeria monocytogenes in the presence of weak acid preservatives and hydrochloric acid. Front. Microbiol. 4:152. doi: 10.3389/fmicb.2013. 00152

This article was submitted to Frontiers in Microbial Physiology and Metabolism, a specialty of Frontiers in Microbiology. Copyright (c) 2013 Diakogiannis, Berberi, Siapi, Arkoudi-Vafea, Giannopoulou and Mastronicolis. This is an openaccess article distributed under the terms of the Creative Commons Attribution License, which permits use, distribution and reproduction in other forums, provided the original authors and source are credited and subject to any copyright notices concerning any third-party graphics etc. 